\title{
Impacto de inseticidas sobre parasitóides da traça-das-crucíferas em repolho, no Distrito Federal ${ }^{(1)}$
}

\author{
Marina Castelo Branco(2) e Maria Alice Medeiros $^{(2)}$
}

\begin{abstract}
Resumo - Este trabalho teve como objetivo identificar os parasitóides da Plutella xylostella (L.) presentes em áreas de cultivo do Distrito Federal, tratadas ou não com inseticidas, onde larvas do inseto foram coletadas. Foram identificados quatro parasitóides: Apanteles sp. (Braconidae), Oomyzus sokolowiskii (Kurdjumov) (Eulophidae), Diadegma sp. (Ichneumonidae) e Actia sp. (Tachinidae). O nível de parasitismo nas áreas não tratadas com inseticidas variou de 5\% a 94\%, enquanto em áreas tratadas variou de $11 \%$ a $87 \%$. A maior parte das larvas de traça-das-crucíferas foram encontradas nas cabeças de repolho ou na parte inferior das folhas da saia das plantas. Esta distribuição de larvas sobre as plantas deve permitir que estas escapem do contato com o inseticida, e, consequientemente, os parasitóides podem sobreviver nas plantas tratadas.
\end{abstract}

Termos para indexação: Plutella xylostella, Brassica oleraceae, parasitismo, inimigos naturais.

\section{Impact of insecticides on Diamondback Moth parasitoids on cabbage in the Federal District of Brazil}

\begin{abstract}
The objective of this work was to identify parasitoids of Diamondback Moth in the Federal District. Larvae of the insect were collected in areas treated with insecticides or in untreated areas. Four species of parasitoids were identified: Apanteles sp. (Braconidae), Oomyzus sokolowiskii (Kurdjumov) (Eulophidae), Diadegma sp. (Ichneumonidae) and Actia sp. (Tachnidae). The total rate of parasitism ranged from $5 \%$ to $94 \%$ in fields untreated with insecticides, while they ranged between $11 \%$ to $87 \%$ in treated ones. Most Diamondback Moth larvae were found on cabbage head and on the underside of outer cabbage leaves. The larvae distribution could allow them to escape insecticide residues and so also allow parasitoid survival.
\end{abstract}

Index terms: Plutella xylostella, Brassica oleraceae, parasitism, natural enemies.

\section{Introdução}

Entre os vários insetos que atacam o repolho, a traça-das-crucíferas é a praga que maiores danos causa à lavoura. Seu controle é efetuado com inseticidas, e os piretróides e fosforados são os grupos mais utilizados.

O uso de inimigos naturais é uma das alternativas para diminuir ou eliminar o uso de inseticidas em lavouras de repolho. No Distrito Federal já foram identificados os parasitóides Apanteles sp. e

\footnotetext{
(1) Aceito para publicação em 18 de abril de 2000.

(2) Embrapa-Centro Nacional de Pesquisa de Hortaliças, Caixa Postal 218, CEP 70359-970, Brasília, DF.

E-mail: marina@cnph.embrapa.br, malice@cnph.embrapa.br
}

Diadegma sp. (Pontes, 1995). No entanto, experimentos de laboratório indicaram que inseticidas piretróides como deltametrina, fosforados como metamidofós e ditiocarbamatos como cartap são altamente tóxicos para parasitóides da traça-dascrucíferas (Talekar \& Yang, 1991; Kao \& Tzeng, 1992). Já o fosforado acefate apresenta baixo grau de toxicidade para adultos de parasitóides da traçadas-crucíferas, e seu uso é sugerido em áreas onde o objetivo é a utilização de parasitóides para o controle biológico (Feng \& Wang, 1984; Kao \& Tzeng, 1992). Embora em testes de laboratório muitos inseticidas tenham se mostrado tóxicos para inimigos naturais, observações de campo indicaram que em áreas de cultivo de repolho pulverizadas intensivamente com inseticidas de diferentes grupos, 
porcentuais de parasitismo de até $90 \%$ foram encontrados (Cordero \& Cave, 1990; Alam, 1992; Dennil \& Pretorius, 1995).

O objetivo deste trabalho foi identificar os parasitóides mais comuns da traça-das-crucíferas no Distrito Federal, quantificar sua sobrevivência em lavouras de repolho tratadas com inseticidas, e avaliar as possíveis causas desta sobrevivência.

\section{Material e Métodos}

Quatrocentas e oitenta plantas de repolho foram transplantadas em maio de 1996 para uma área do campo experimental da Embrapa-Centro Nacional de Pesquisa de Hortaliças (CNPH). As plantas foram mantidas sem pulverização de inseticidas até o final do ciclo da cultura. Nos dias 22 e 31 de julho e 9, 21 e 30 de agosto, 30 plantas foram escolhidas ao acaso, em cada oportunidade, na área do experimento, e larvas de terceiro e quarto estádio de traça-das-crucíferas encontradas sobre as plantas foram coletadas. Estas foram mantidas em caixas de plástico com folhas de repolho, no interior de câmaras climatizadas tipo BOD, à temperatura de $20^{\circ} \mathrm{C} \pm 1^{\circ} \mathrm{C}$ e 13 horas de fotofase até o estádio de pupa. As pupas formadas foram acondicionadas individualmente em cápsulas de gelatina, para verificar o tipo de inseto emergido (adultos de traça-das-crucíferas ou parasitóides da praga). Em caso de emergência de parasitóides já conhecidos no Distrito Federal - Apanteles sp. e Diadegma sp. -, estes foram identificados no próprio Laboratório de Entomologia da Embrapa-CNPH, conservados em álcool 70\% e posteriormente enviados ao Museu Britânico para confirmação da identificação das espécies. Parasitóides desconhecidos foram conservados em álcool 70\% e enviado(s) ao CIRAD para identificação.

A fim de obter a maior diversidade possível de parasitóides da traça-das-crucíferas e avaliar a presença destes em áreas não tratadas com inseticidas ou em áreas tratadas com inseticidas, coletas esporádicas de larvas da praga foram feitas em áreas de repolho localizadas na Embrapa-CNPH e em propriedades rurais nos Núcleos Rurais de Alexandre Gusmão, Brazlândia, Vargem Bonita e Planaltina. Essas áreas foram tratadas com acefate, Bacillus thuringiensis, cartap, deltametrina, fentoato e metamidofós.

A fim de avaliar no campo o efeito do inseticida cartap - tóxico para parasitóides de traça-das-crucíferas em testes de laboratório (Talekar \& Yang, 1991) - e acefate - não tóxico para parasitóides de traça-das-crucíferas em testes de laboratório (Feng \& Wang, 1984; Kao \& Tzeng, 1992) - sobre os parasitóides de traça-dascrucíferas, 420 plantas de repolho foram transplantadas em julho de 1996. Esse campo foi subdividido em três áreas, de 140 plantas cada uma. A partir dos 22 dias após o transplante, semanalmente a primeira subárea foi pulverizada com acefate; a segunda, com cartap, e a terceira, deixada sem pulverização. Em agosto e novembro, foram coletadas todas as larvas da traça-das-crucíferas de terceiro e quarto estágio encontradas na cabeça de repolho (cabeça e quatro folhas ao redor) e nas folhas da saia, sobre um total de 20 plantas de cada tratamento. As larvas foram criadas em laboratório até atingirem o estágio de pupa, e em seguida, colocadas individualmente, em cápsulas de gelatina, para avaliação da emergência de adultos da praga ou de parasitóides.

\section{Resultados e Discussão}

Nas amostragens realizadas em áreas não pulverizadas com inseticidas, foram coletadas quatro espécies de parasitóides da traça-das-crucíferas: Apanteles sp. (Braconidae), Oomyzus sokolowiskii (Eulophidae), Diadegma sp. (Ichneumonidae) e Actia sp. (Tachinidae). Foram obtidos ainda dois Chalcididae (Conura sp.1 e Conura sp.2), os quais possivelmente são hiperparasitóides das espécies anteriores.

No levantamento realizado no período de julho a agosto de 1996 na área da Embrapa-CNPH, observouse que, das larvas coletadas no campo, a emergência de adultos da traça-das-crucíferas variou entre $52 \%$ e $73 \%$ com as maiores porcentagens de emergência no início do período (Figura 1).

Diadegma sp. foi o parasitóide mais abundante no período avaliado, com um porcentual máximo de parasitismo de $22 \%$ na quarta semana (Figura 1). Apanteles sp. foi registrado apenas na última semana, quando $14 \%$ das larvas estavam parasitadas. $\mathrm{O}$ ingresso tardio de Apanteles sp. na área de cultivo pode ser um dos fatores responsáveis pela ausência inicial observada. O parasitóide foi observado em Brazlândia, no mesmo ano, em agosto de 1996 (Tabela. 2). Além do mais, Pontes (1995) observou baixas densidades populacionais do parasitóide no período de julho a setembro de 1993 na área da Embrapa-CNPH.

A porcentagem de larvas parasitadas por O. sokolowiskii foi baixa durante todo o período avaliado, variando de $1 \%$ a $5 \%$ (Figura 1). A causa desse baixo porcentual de parasitismo pode estar relacionada ao baixo poder competitivo do parasitóide, ou também a condições ambientais desfavoráveis. 


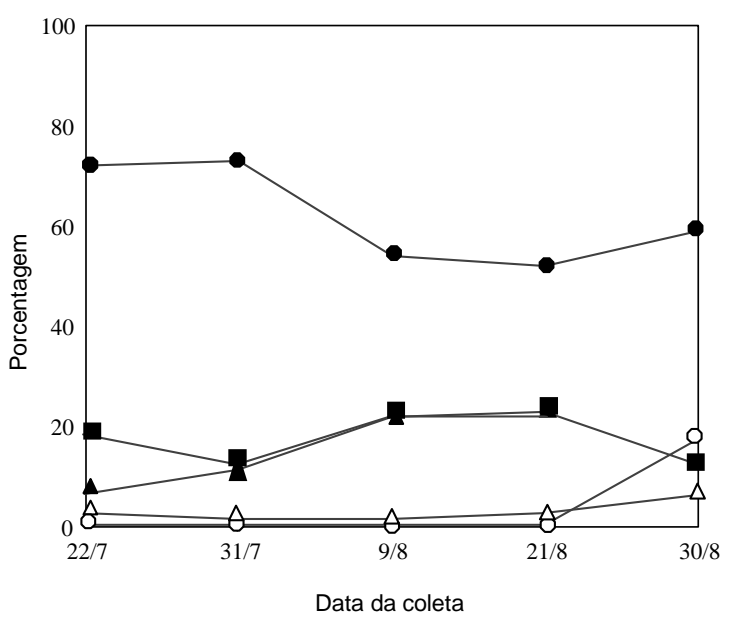

Figura 1. Porcentual de emergência de adultos de traça-

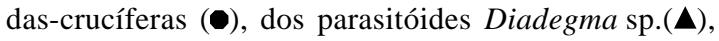
Apanteles sp.(O), Oomyzus sokolowiskii $(\Delta)$ e pupas não emergidas ( $\square$ ), em uma área de cultivo de repolho não pulverizada com inseticida. O número total de larvas coletadas em 22/7, 31/7, 9/8, 21/8, 30/8 foi, respectivamente, 211, 395, 279, 468, 155. Brasília, 1996.

Talekar \& Hu (1996) observaram que a temperatura influencia o crescimento populacional de O. sokolowiskii, pois a $20^{\circ} \mathrm{C}$ somente $50 \%$ das larvas da traça-das-crucíferas foram parasitadas, enquanto a $35^{\circ} \mathrm{C}$ o porcentual subiu para $90 \%$. Como a temperatura média no Distrito Federal durante o período de amostragem foi de $23^{\circ} \mathrm{C}$, esta temperatura pode ter afetado o crescimento populacional deste parasitóide.

Nas avaliações realizadas foram também observados que $11 \%$ e $24 \%$ das pupas não emergiram, por causas não identificadas (Figura 1). Fatores ambientais que impediram o completo desenvolvimento das larvas da traça-das-crucíferas ou dos parasitóides, ou ainda doenças causadas por vírus, bactérias ou fungos podem estar entre os fatores que causaram esta mortalidade.

Levantamentos realizados esporadicamente em outras áreas não tratadas com inseticidas encontraram porcentuais totais de parasitismo de até $94 \%$ (Tabela 1). Nessas áreas, Diadegma sp. foi normalmente predominante nos meses de abril a agosto, quando a temperatura média na região se situa ao redor de $23^{\circ} \mathrm{C}$, atingindo um pico de $32 \%$ de parasitismo. Talekar et al. (1992) observaram que temperaturas de $15^{\circ} \mathrm{C}$ a $23^{\circ} \mathrm{C}$ eram as ideais para o desenvolvimento de D. semiclausum. Apanteles sp. ocorreu predominantemente nos meses de outubro e novembro, quando as temperaturas médias são mais elevadas, e esteve praticamente ausente no período de abril a agosto. Quando este parasitóide foi predominante, porcentuais de parasitismo de até $83 \%$ foram observados (Tabela 1).

O parasitóide Actia sp. é referido pela primeira vez como parasitóide da traça-das-crucíferas. Parasitóides deste gênero foram encontrados no Canadá e Estados Unidos, parasitando principalmente Lepidópteros da família Tortricidae (O`Hara, 1991). Na Austrália, foram encontradas até $40 \%$ das larvas de Crocidosema plebiana (Lepidoptera: Tortricidae) parasitadas por Actia sp. (Bishop \& Blood, 1978). Em áreas não pulverizadas da Embrapa-CNPH, foi observado um porcentual máximo de parasitismo por Actia sp. de 33\% em setembro de 1995 (Tabela 1).

A avaliação de parasitóides em áreas de agricultores e em áreas da Embrapa-CNPH, todas tratadas com inseticidas, mostrou que pelo menos uma espécie de parasitóide foi encontrada (Tabela 2). Os porcentuais mais elevados de parasitismo foram encontrados nas áreas tratadas com acefate, cartap e deltametrina. Nessas áreas, o porcentual de parasitismo variou de $36 \%$ a $87 \%$. As áreas tratadas com os inseticidas fosforados metamidofós ou fentoato apresentaram porcentuais de parasitismo total inferior a $30 \%$. Aparentemente, esses fosforados foram os que causaram maiores reduções nos índices de parasitismo (Tabela 2).

$\mathrm{O}$ efeito da aplicação dos inseticidas acefate e cartap sobre a sobrevivência de parasitóides da traça-das-crucíferas foi comparado com sua sobrevivência em áreas não tratadas, em agosto e em novembro de 1996. Em agosto, foi encontrado um porcentual de parasitismo total de $72 \%$ na área não tratada, e $60 \%$ dos parasitóides foram encontrados nas folhas da saia (Tabela 3). Diadegma sp. foi o parasitóide predominante nesta época, parasitando $52 \%$ das larvas da traça-das-crucíferas. Nas áreas tratadas com cartap ou acefate, observou-se uma redução do parasitismo, já que apenas $51 \%$ das larvas estavam parasitadas nos dois tratamentos (Tabela 3). Em áreas tratadas com cartap, a maior proporção dos 
Tabela 1. Porcentual de emergência de traça-das-crucíferas ou parasitóides e porcentual de larvas de traça-das-crucíferas não emergidas. Coleta de larvas de terceiro e quarto estágio em áreas não tratadas com inseticidas. Brasília, 1995, 1996 e 1998.

\begin{tabular}{|c|c|c|c|c|c|c|c|c|c|}
\hline Data & Local de coleta & $\begin{array}{c}\text { Larvas } \\
\text { coletadas }\left(\mathrm{n}^{\mathrm{o}}\right)\end{array}$ & $\begin{array}{c}\text { Plutella } \\
\text { xylostella }\end{array}$ & $\begin{array}{l}\text { Pupas não } \\
\text { emergidas }\end{array}$ & $\begin{array}{l}\text { Parasitismo } \\
\text { total }\end{array}$ & $\begin{array}{l}\text { Diadegma } \\
\text { sp. }\end{array}$ & $\begin{array}{c}\text { Oomyzus } \\
\text { sokolowiskii }\end{array}$ & $\begin{array}{l}\text { Apanteles } \\
\text { sp. }\end{array}$ & Actia sp. \\
\hline & & & \multicolumn{7}{|c|}{ 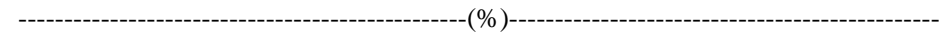 } \\
\hline & & & & & & 1995 & & & \\
\hline Junho & $\begin{array}{l}\text { Alexandre } \\
\text { Gusmão }\end{array}$ & 82 & 68 & 0 & 32 & 32 & 0 & 0 & 0 \\
\hline Junho & Vargem Bonita & 78 & 50 & 20 & 30 & 30 & 0 & 0 & 0 \\
\hline Agosto & Embrapa-CNPH & 178 & 40 & 23 & 37 & 13 & 23 & 1 & 0 \\
\hline \multirow[t]{2}{*}{ Setembro } & Embrapa-CNPH & 42 & 35 & 3 & 62 & 12 & 0 & 17 & 33 \\
\hline & & & \multicolumn{7}{|c|}{1996} \\
\hline Abril & Embrapa-CNPH & 33 & 66 & 0 & 34 & 15 & 15 & 4 & 0 \\
\hline Abril & Vargem Bonita & 90 & 79 & 13 & 8 & 8 & 0 & 0 & 0 \\
\hline Maio & Embrapa-CNPH & 67 & 40 & 45 & 15 & 12 & 3 & 0 & 0 \\
\hline Outubro & Embrapa-CNPH & 124 & 6 & 0 & 94 & 6 & 3 & 83 & 2 \\
\hline Novembro & Embrapa-CNPH & 44 & 27 & 20 & 53 & 0 & 3 & 43 & 7 \\
\hline \multirow[t]{2}{*}{ Novembro } & Embrapa-CNPH & 43 & 28 & 18 & 54 & 0 & 3 & 44 & 7 \\
\hline & & & \multicolumn{7}{|c|}{1998} \\
\hline Junho & Embrapa-CNPH & 218 & 84 & 5 & 11 & 5 & 6 & 0 & 0 \\
\hline Julho & Brazlândia & 234 & 33 & 29 & 38 & 32 & 6 & 0 & 0 \\
\hline Julho & Embrapa-CNPH & 641 & 70 & 23 & 7 & 6 & 1 & 0 & 0 \\
\hline
\end{tabular}

parasitóides foi encontrada nas folhas da saia (31\%), enquanto nas áreas tratadas com acefate, a maior parte dos parasitóides foi encontrada nas cabeças de repolho $(28 \%)$ (Tabela 3). Diadegma sp. foi o parasitóide predominante no tratamento cartap, com um total de $31 \%$ de larvas parasitadas. Já no tratamento acefate, Apanteles sp. foi predominante, com $28 \%$ das larvas parasitadas. A causa da predominância de Apanteles sp. no tratamento acefate não pôde ser identificada, mas é possível que os inseticidas apresentem impactos diferentes sobre os parasitóides.

A maior porcentagem de adultos da traça-dascrucíferas emergiram de larvas coletadas na cabeça de repolho, independentemente do tratamento (Tabela 3). A maior parte dessas larvas foi coletada no interior das folhas que compunham as cabeças do repolho que começavam a se formar. Um dos fatores que pode explicar esta maior sobrevivência de larvas nas cabeças de repolho é sua localização, que pode dificultar o acesso dos parasitóides, constituindo um escape à ação do inimigo natural.

A porcentagem de pupas não emergidas variou de $4 \%$ na área não pulverizada, a $31 \%$ na área tratada com cartap e os maiores porcentuais de larvas não emergidas foram encontrados nos tratamentos com inseticida (Tabela 3). É possível que a aplicação desses produtos tenha contribuído para reduzir a emergência de larvas a partir da ação de um efeito residual.

Ao contrário do observado em agosto, Apanteles sp. foi o parasitóide predominante em novembro, com mais de $79 \%$ do total das larvas parasitadas. A maior porcentagem desses parasitóides foi encontrada na parte inferior das folhas da saia, como havia sido observado em agosto (Tabela 4). A traça-das-crucíferas foi encontrada em porcentuais aproximadamente semelhantes quando foi feita a comparação entre o porcentual de larvas na cabeça e nas folhas da saia, ao contrário do verificado em agosto, quando o maior porcentual de larvas foi observado nas cabeças. A ocorrência de chuvas anteriormente ao período de avaliação deve ter sido a responsável por esta diferença de resultados. Isto porque com as chuvas, a água se acumula nas cabeças de repolho, causando afogamento das larvas (Harcourt, 1963; Castelo Branco, 1997).

A presença de parasitóides de larvas da traça-dascrucíferas em áreas pulverizadas intensivamente com inseticidas foi constatada em áreas de cultivo de re- 
Tabela 2. Porcentual de emergência de traça-das-crucíferas ou parasitóides e porcentual de pupas de traça-das-crucíferas não emergidas. Coleta de larvas de terceiro e quarto estágio em áreas tratadas com inseticidas. Brasília, 1995, 1996 e 1998.

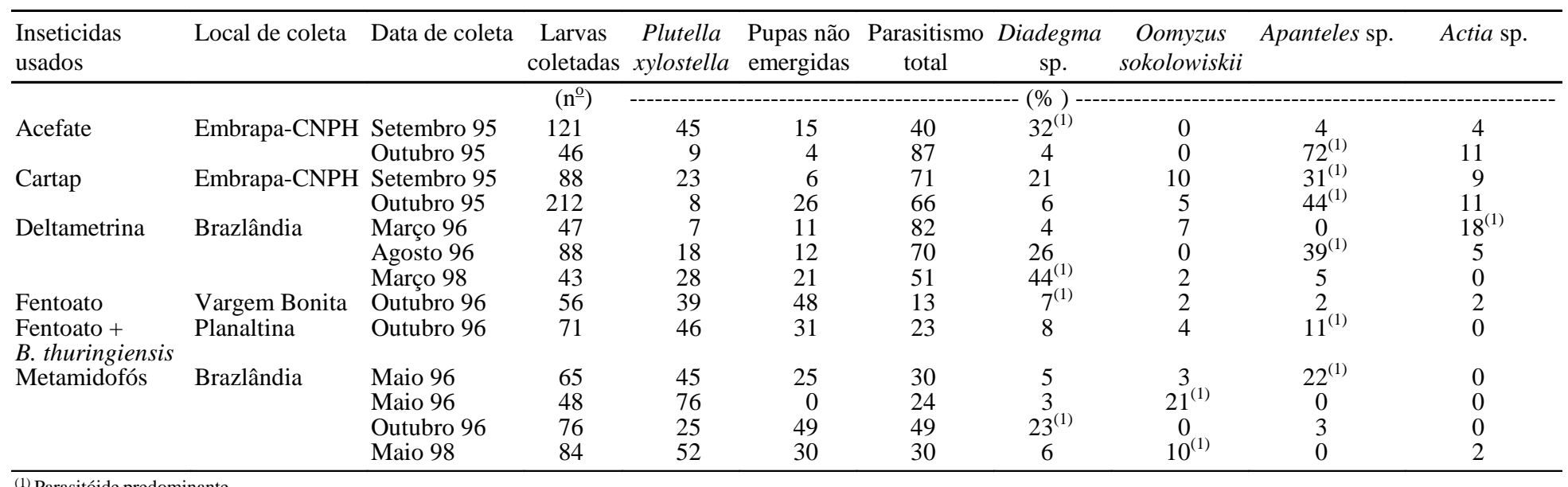

(1) Parasitóide predominante.

Tabela 3. Porcentual de emergência de traça-das-crucíferas ou parasitóides e porcentual de pupas de traça-das-crucíferas não emergidas quando as larvas de traça-das-crucíferas foram coletadas sobre as cabeças de repolho ou sobre as folhas da saia. Brasília, agosto de 1996.

\begin{tabular}{|c|c|c|c|c|c|c|c|c|c|c|c|}
\hline \multirow[t]{2}{*}{ Tratamento } & \multirow{2}{*}{$\begin{array}{c}\text { Larvas } \\
\text { coletadas/ } \\
20 \text { plantas }\end{array}$} & \multicolumn{2}{|c|}{ Plutella xylostella } & \multicolumn{2}{|c|}{ Parasitismo total } & \multicolumn{2}{|c|}{ Apanteles sp. } & \multicolumn{2}{|c|}{ Diadegma sp. } & \multicolumn{2}{|c|}{ Não emergido } \\
\hline & & Cabeça & $\begin{array}{c}\text { Folhas da } \\
\text { saia }\end{array}$ & Cabeça & $\begin{array}{c}\text { Folhas da } \\
\text { saia }\end{array}$ & Cabeça & $\begin{array}{c}\text { Folhas da } \\
\text { saia }\end{array}$ & Cabeça & $\begin{array}{c}\text { Folhas da } \\
\text { saia }\end{array}$ & Cabeça & $\begin{array}{c}\text { Folhas da } \\
\text { saia }\end{array}$ \\
\hline Cartap & 62 & 15 & 2 & 20 & 31 & 10 & 10 & 10 & 21 & 0 & 31 \\
\hline Acefate & 40 & 25 & 0 & 28 & 23 & 13 & 15 & 15 & 8 & 23 & 1 \\
\hline Testemunha & 101 & 16 & 8 & 12 & 60 & 12 & 8 & 0 & 52 & 0 & 4 \\
\hline
\end{tabular}




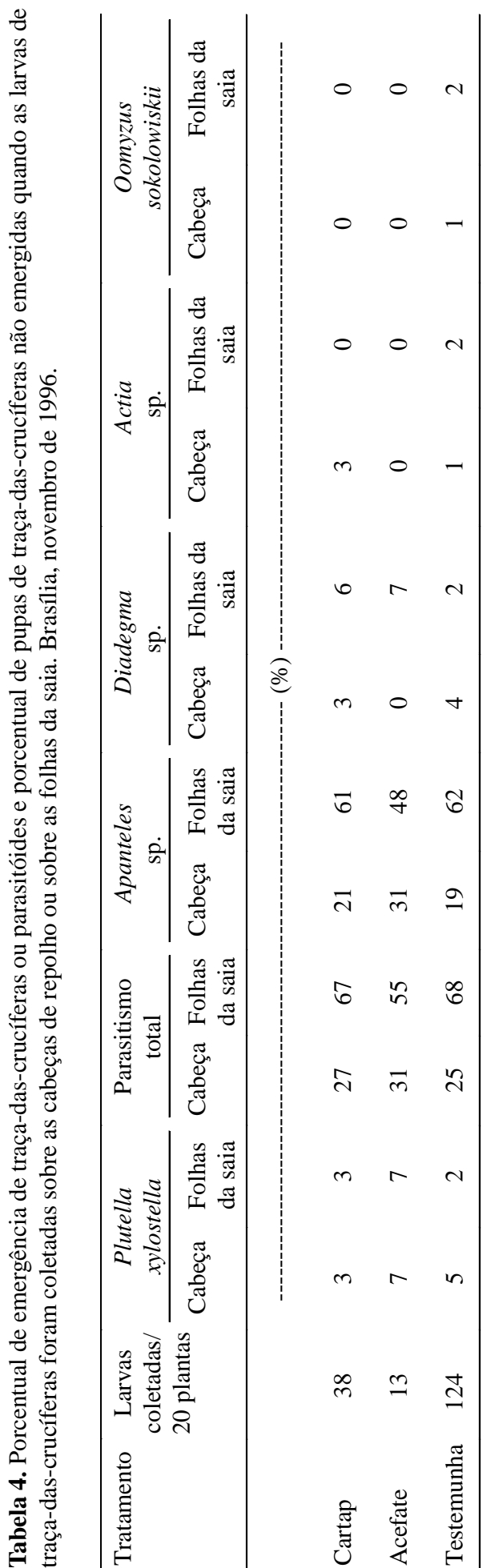

polho do Distrito Federal. Uma das causas que podem contribuir para a ocorrência de parasitismo em áreas tratadas com inseticidas é a distribuição irregular destes produtos sobre as plantas de repolho. Castelo Branco (1997) observou que quando plantas de repolho eram pulverizadas, a calda do inseticida não atingia a base das cabeças de repolho nem tampouco a parte inferior das folhas da saia, locais preferidos da planta pelas larvas da traça-dascrucíferas.

Outra causa que poderia favorecer a sobrevivência de parasitóides em áreas tratadas com piretróides e fosforados pode ser a resistência de populações da praga do Distrito Federal a estes inseticidas (Castelo Branco \& Gatehouse, 1997). Com relação aos piretróides, sabe-se que um dos mecanismos de resistência é uma maior produção de enzimas, que degrada mais rapidamente estes produtos (Hama, 1987; Doichuanngam \& Thornhill, 1989; Yu, 1993; Konno \& Shishido, 1994), impedindo, assim, a morte das larvas. Se com essa degradação os inseticidas não afetarem o desenvolvimento dos parasitóides, estes podem sobreviver em áreas tratadas. A fim de confirmar esta hipótese, o impacto destes mecanismos na sobrevivência dos parasitóides necessita ser identificado.

\section{Conclusões}

1. Os parasitóides da traça-das-crucíferas identificados no Distrito Federal são: Apanteles sp., Oomyzus sokolowiskii, Diadegma sp. e Actia sp.

2. Diadegma sp. ocorre em maiores proporções nos meses de abril a agosto e Apanteles sp. nos meses de setembro a novembro.

3. Parasitóides da traça-das-crucíferas são encontrados em áreas tratadas intensivamente com inseticidas ou em áreas não tratadas.

\section{Agradecimentos}

À Dra. Geni L. Villas Bôas e ao Comitê de Publicações da Embrapa-Centro Nacional de Pesquisa de Hortaliças, pela revisão do manuscrito; aos Drs. JeanMichel Vassal (CIRAD) e Mike Fitton, Mark Shaw e 
John Noyes (Museu Britânico), pela identificação dos parasitóides; ao Dr. Neville V. B. dos Reis, pelos dados meteorológicos; a Hozanan P. Chaves e Ronildo C. Gonçalves, pelo auxílio nos trabalhos de campo e laboratório.

\section{Referências}

ALAM, M. M. Diamondback moth and its natural enemies in Jamaica and some other Caribbean islands. In: DIAMONDBACK MOTH AND OTHER CRUCIFER PESTS INTERNATIONAL WORKSHOP, 2., 1990, Tainan. Proceedings... Tainan : Asian Vegetable Research and Development Center, 1992. p. 233-243.

BISHOP, A. L.; BLOOD, P. R. B. Temporal distribution, biology and life history of the cotton tipworm, Crocidosema plebiana Zeller, on cotton in the SouthEastern Queensland region. Australian Journal of Zoology, Collingwood, v. 26, p. 147-152, 1978.

CASTELO BRANCO, M. Insecticide resistance in Plutella xylostella (Linnaeus) (Yponomeutidae) in the Federal District, Brazil: effects of local and long range movements of moth. Bangor : University of Wales, 1997. 196 p. Ph.D. Thesis.

CASTELO BRANCO, M.; GATEHOUSE, A. G. Insecticide resistance in Plutella xylostella (L.) (Lepidoptera: Yponomeutidae) in the Federal District, Brazil. Anais da Sociedade Entomológica do Brasil, Piracicaba, v. 26, p. 75-79, 1997.

CORDERO, J.; CAVE, R. D. Parasitismo de Plutella xylostella L. (Lepidoptera: Plutellidae) por Diadegma insulare (Cresson) (Hymenoptera: Ichneumonidae) en cultivo de repollo (Brassica oleracea var. capitata) en Honduras. Manejo Integrado de Plagas, Turrialba, v. 16, p. 19-22, 1990.

DENNIL, G. B.; PRETORIUS, W. L. The status of diamondback moth, Plutella xylostella (Linnaeus) (Lepidoptera: Plutellidae), and its parasitoids on cabbages in South Africa. African Entomology, Pretoria, v. 3, p. $65-$ 71, 1995.

DOICHUANNGAM, K.; THORNHILL, R. A. The role of non-specific esterases in insecticide resistance to malathion in the diamondback moth. Comparative Biochemistry and Physiology, New York, v. 93C, p. 81-85, 1989.

FENG, H. T.; WANG, T. C. Selectivity of insecticides to Plutella xylostella (L.) and Apanteles plutellae Kurd. Plant Protection Bulletin, Wufeng, v. 26, p. 275-284, 1984.
HAMA, H. Development of pyrethroid resistance in the diamondback moth, Plutella xylostella Linné (Lepidoptera: Yponomeutidae). Applied Entomology and Zoology, Tokyo, v. 22, p. 166-175, 1987.

HARCOURT, D. G. Biology of cabbage caterpillars in eastern Ontario. Entomological Society of Ontario Proceedings, Kingston, v. 93, p. 61-75, 1963.

KAO, S. S.; TZENG, C. C. Toxicity of insecticides to Cotesis plutellae, a parasitoid of the diamondback moth. In: DIAMONDBACK MOTH AND OTHER CRUCIFER PESTS INTERNATIONAL WORKSHOP, 2., 1990, Tainan. Proceedings... Tainan : Asian Vegetable Research and Development Center, 1992. p. 287-296.

KONNO, Y.; SHISHIDO, T. A relationship between the chemical structure of organophosphates and insensitivity of acetylcholinesterase in the diamondback moth, Plutella xylostella L. (Lepidoptera: Yponomeutidae). Applied Entomology and Zoology, Tokyo, v. 29, p. 595-597, 1994.

O’HARA, J. E. Revision of neartic species of Actia Robineau-Desvoidy (Diptera: Tachnidae). Canadian Entomologist, Ottawa, v. 123, p. 745-776, 1991.

PONTES, R. G. M. S. Interrelation entre la teigne des crucifers Plutella xylostella (L.) (Lep: Yponomeutidae), son parasitoidee Diadegma sp. (Hym: Ichneumonidae) et la bacterie entomopathogene Bacillus thuringiensis Berliner. Montpellier : Ecole Nationale Superieure Agronomique de Montpellier, 1995. 162 p. Thèse de Doctorat.

TALEKAR, N. S.; HU, W. J. Characteristics of parasitism of Plutella xylostella (Lep., Plutellidae) by Oomyzus sokolowiskii. Entomophaga, Paris, v. 41, p. 45-52, 1996.

TALEKAR, N. S.; YANG, J. C. Characteristic of parasitism of diamondback moth by two larval parasites. Entomophaga, Paris, v. 36, p. 95-104, 1991.

TALEKAR, N. S.; YANG, J. C.; LEE, S. T. Introduction of Diadegma semiclausum to control diamondback moth in Taiwan. In: DIAMONDBACK MOTH AND OTHER CRUCIFER PESTS INTERNATIONAL WORKSHOP, 2., 1990, Tainan. Proceedings... Tainan : Asian Vegetable Research and Development Center, 1992. p. 263-270.

YU, S. J. Inheritance of insecticide resistance and microsomal oxidases in the diamondback moth (Lepidoptera: Yponomeutidae). Journal of Economic Entomology, Lanham, v. 86, p. 680-683, 1993. 